\section{Hypoglycemic effects of leaf extracts of Moringa oleifera and Vitex simplicifolia on blood glucose level of Wistar rat}

\author{
M. Abdulrazak, ${ }^{1}$ M.A. Salim, ${ }^{2}$ \\ Abbas Bubakar El-ta'alu² \\ ${ }^{1}$ Department of Internal Medicine, \\ Aminu Kano Teaching Hospital, Kano; \\ ${ }^{2}$ Department of Human Physiology, \\ Faculty of Basic Medical Sciences, \\ College of Health Sciences, Bayero \\ University, Kano, Nigeria
}

\begin{abstract}
Diabetes mellitus (DM) is as a disorder that is characterized by increase in blood sugar levels, as well as disturbances in the metabolism of the three main classes of food. Whole plants or their parts serve as alternatives in the treatment of many diseases and, have, for a time immemorial, been very important in the health care delivery in many countries. The objective of this study was to compare the relative antihyperglycemic properties of Moringa oleifera and Vitex simplicifolia, as well as the reference drug glibenclamide, on blood sugar levels. DM was induced via intraperitoneal injection of alloxan monohydrate; levels of glucose in circulating blood were measured using a glucometer, by tail snip method. Potent oral hypoglycemic properties and thus, a fast onset of anti-diabetic activity was more pronounced in Vitexsimplicifolia than in Moringa oleifera. The two were more potent than the reference drug, glibenclamide. The studied leaf extracts are relatively safe and could be used in the treatment of Diabetes mellitus.
\end{abstract}

\section{Introduction}

Diabetes mellitus (DM) is a chronic disease that is characterized by increase in circulating glucose level, as well as disturbances in the metabolism of carbohydrates, proteins and fats; it is caused either when the pancreas does not produce enough insulin hormone or when the body cannot effectively utilize the insulin it produces. ${ }^{1}$ The human body maintains blood glucose level at a relatively constant level, above which a condition of hyperglycemia sets in, which is life threatening.

The prevalence of diabetes significantly increased in the last decade. The number of people with diabetes worldwide has risen from 108 to 422 million in 1980 and 2014, respectively. ${ }^{2}$ The global prevalence of the disease among adults over 18 years of age has risen from 4.7 to $8.5 \%$ in 1980 and 2014, respectively. ${ }^{3}$ There were 382 million ( $8.3 \%$ of adult global population) people worldwide with diabetes by end of 2013 , out of which $80 \%$ were from low- and middle-income countries; this number is expected to reach 592 million by 2035.4

The estimated prevalence of diabetes in sub-Saharan Africa is $1 \%$ in rural areas, and ranges from $5-7 \%$ in urban towns. ${ }^{5}$ Currently, the prevalence of the disease in African continent is about 20 million people (with about $62 \%$ undiagnosed) and with a projection of 41.4 million people by 2035.4

For the past three decades in Nigeria, diabetes has been increasing steadily; it was reported that, the country has the greatest number of diabetic patients in Africa, with an estimated 3.9 million people (or an extrapolated prevalence of $4.99 \%$ ) of the adult population aged $20-79$-year-old. ${ }^{6}$ This will ultimately lead to major healthcare problems.

Out of the four classes of diabetes recognized, types I and II, as well as gestational diabetes are discussed herein: Type I, previously known as Insulin Dependent Diabetes mellitus (IDDM), is a severe form of the disease that is caused by insufficient production of the hormone insulin, which results in disturbances of the metabolism of carbohydrates, proteins and fats; it appears in childhood or adolescence and is accompanied by excessive thirst, frequent urination, as well as acidosis that can even lead to wasting of muscle. ${ }^{7}$ The life expectancy of a child with Type I diabetes in rural areas of Nigeria is as low as seven months, mainly because of limited access to the hormone insulin, which is very expensive; as well as lack of infrastructure within the healthcare system. ${ }^{8}$ It has been reported that, while $90 \%$ of Type I diabetic children live for six years after diagnosis in the United States of America, in the sub-Saharan Africa, only $1 \%$ of children survives up to that. ${ }^{1}$

Type II diabetes was previously known as Non-Insulin-Dependent Diabetes mellitus (NIDDM); it typically appears in adulthood and is characterized by obesity and an inactive lifestyle. This type is the most commonly documented in Nigeria and accounts for about $90-95 \%$ of all cases; ${ }^{9}$ it is influenced by such factors as: ignorance of the disease, self-care management, patient's age, gender, level of education, location of healthcare delivery centers, socio-economic status, type of occupation and financial status. ${ }^{10}$

Gestational diabetes is caused by glucose intolerance detected during pregnancy (24 weeks and above), and is common
Correspondence: Abbas Bubakar El-ta'alu, Department of Human Physiology, Faculty of Basic Medical Sciences, College of Health Sciences, Bayero University, Kano-Nigeria. Tel.: +2348109716223

E-mail: abeltaalu.pys@buk.edu.ng

Key words: Diabetes mellitus, Moringa oleifera, Vitex simplicifolia, glibenclamide.

Contributions: The authors contributed equally.

Conflict of interest: The authors declare no potential conflict of interest.

Funding: None.

Received for publication: 29 December 2018. Revision received: 16 August 2019.

Accepted for publication: 22 August 2019.

This work is licensed under a Creative Commons Attribution NonCommercial 4.0 License (CC BY-NC 4.0).

${ }^{C}$ Copyright: the Author(s), 2019

Licensee PAGEPress, Italy

Pyramid Journal of Medicine 2019; 2:36

doi:10.4081/pjm.2019.36

among obese women. ${ }^{9}$ Women diagnosed with diabetes within this period of pregnancy are more likely to have pre-gestational diabetes. ${ }^{9}$

Symptoms of diabetes may develop fast in type I but may be slight and not obvious or may at the same time, be completely absent in type II; the symptoms include: polyuria (excessive urination), polydipsia (increased thirst), and polyphagia (excessive eating); weight loss and irreducible fatigue; tingling and numbness in the hands and feet; pronounced dry skins; sores; infections more than usual; nausea; vomiting or stomach pain; general irritability.

Alloxanis a urea derivative that selectively destroys $\beta$-cells of pancreatic islets; its action involves oxidation of cysteine residues, which leads to the formation of reactive sulfenic acid (-SOH groups), which in turn, may lead to changes in the structural conformation and/or function of a protein for example, inhibition of glucokinase enzyme, ${ }^{11}$ The selective uptake of alloxan has been attributed to its structural similarity with glucose. ${ }^{12}$

Complementary and alternative methods of treatment are widely utilized by diabetic patients worldwide; medicinal plants containing inherent active ingredients, for the time immemorial, have been integral components in the healthcare delivery systems of many countries. ${ }^{13}$ It has been shown 
that, traditional method of controling blood glucose level could be better than currently used conventional drugs. ${ }^{14}$ Plants possess a variety of ingredients, which can ameliorate a disease condition by acting on a variety of targets. ${ }^{15}$ Traditional anti-diabetic properties of these plants might provide a very important clue in either the development of new oral hypoglycemic drugs or simple dietary adjuncts to existing therapies. Despite their significance in the regulation of blood glucose levels in Type II diabetes, sulfonylureas and biguanides are often unable to lower these levels to within the normal range. ${ }^{14}$ It has also been shown that, normal pattern of glucose homeostasis in most Type I diabetics are not re-established by even insulin therapy, over-vigorous procedure with which may lead to increased risk of hypoglycemia. ${ }^{16}$

Moringa oleifera (Drumstick or Horseradish) known as Zogale in Hausa language, Nigeria; Okweoyibo in Igbo, and Ewe Igbale in Yoruba, is also called the 'miracle tree', since all its parts are edible and valued in nutrition and as a traditional medicine for abortion, ${ }^{16}$ treatment of diabetes, as well as in the treatment of diarrhea, epilepsy, hysteria and as a diuretic. ${ }^{17} \mathrm{~A}$ number of investigators have shown that, aqueous extract of Moringa oleifera contains flavonoids, alkaloids, sapomins, tannins, anthraquinone, cardiac glycosides and reducing sugars. ${ }^{18}$

Vitex simflicifolia is commonly called Dinyar Birin (Hausa language, Nigeria). The plant is widely distributed in tropical West Africa and some East African countries including Uganda, Kenya and Tanzania, and high rainfall areas. ${ }^{19}$ The leaves and its edible fruits are used in traditional medicine for the treatment of malaria, skin diseases, toothache and dermatitis. ${ }^{20}$

The aim of this study was to compare the relative anti-hyperglycemic properties of Moringa oleifera and Vitex simplicifolia, as well as the reference drug glibenglyclamide, on blood glucose levels.

\section{Materials and Methods}

After authentication, leaves of Moringa oleifera and Vitex simplicifolia were dried and ground to semi-powdered forms, from which respective extracts were prepared. Three hundred grams of sample powders were separately dissolved in 2 liters of distilled water and kept at room temperature for 48 hours, filtrates were then concentrated and weighed. Prior to administering to experimental animals, extracts were solubilized in distilled water.

Fifty 12-months old male Wistar rats of between $170 \mathrm{~g}$ and $200 \mathrm{~g}$ were used; they were kept for 2 weeks in the laboratory to acclimatize and were ad libitum fed with Grower's mash (Vital feed, Kano State, Nigeria) and water. In carrying out all procedures, principles and guidelines of animal care and use in intramural program of the American National Institute of Health were followed.

\section{Induction of diabetes in rats}

DM was induced intraperitonially administering prepared alloxan monohydrate solution into each rat after overnight fast, to make them more susceptible to developing diabetes. Baseline blood glucose levels of rats were measured by tail snip method using a glucometre. In order to avoid initial hypoglycemia after alloxan administration, animals were fed only with glucose solution. Subsequent blood glucose levels of the rats were measured 72 hours post alloxan injection. Hyperglycemia was confirmed after 5 days and rats with blood glucose level of $\geq 200 \mathrm{mg} / \mathrm{dL}$ were considered diabetic and were used in this study. ${ }^{21}$

Though the acute toxicity study of the leaf extract in this work was found to be above $5000 \mathrm{mg} / \mathrm{kg} /$ per oral, based on the doses used earlier by other researchers, 300 $\mathrm{mg} / \mathrm{kg} /$ oral for each extract were used in this study. ${ }^{22}$

Forty Wistar rats were divided into: Group $1(\mathrm{n}=5)$ : Normoglycemic rats administered $5 \mathrm{~mL} / \mathrm{kg} /$ per oral with distilled water.
Group 2 ( $\mathrm{n}=5)$ : Normoglycemic rats administered $300 \mathrm{mg} / \mathrm{kg} /$ per oral with Moringa oleifera.

Group $3(\mathrm{n}=5)$ : Normoglycemic rats administered $300 \mathrm{mg} / \mathrm{kg} /$ per oral with Vitex simplicifolia.

Group $4(n=5)$ : Diabetic rats administered with $10 \mathrm{mg} / \mathrm{kg} /$ per oral with glibenclamide. $^{23}$

Twenty diabetic rats were also divided into: Group $5(\mathrm{n}=5)$ : administered $5 \mathrm{~mL} / \mathrm{kg} / \mathrm{per}$ oral with distilled water.

Group $6(\mathrm{n}=5)$ : administered $300 \mathrm{mg} / \mathrm{kg} / \mathrm{per}$ oral with Moringa oleifera.

Group 7 ( $\mathrm{n}=5)$ : administered 300mg/kg/per oral with Vitex simplicifolia.

Group $8(\mathrm{n}=5)$ : administered $10 \mathrm{mg} / \mathrm{kg} /$ oral with glibenclamide (standard drug). ${ }^{24}$

Result of acute toxicity study with of Moringa oleifera extract showed a safe range. The $\mathrm{LD}_{50}$ of the leaf extract was found to be above $5000 \mathrm{mg} / \mathrm{kg} /$ per oral and this agrees with earlier reports by Nagy and Mohammed, ${ }^{23}$ who reported that, the plant leaves were relatively safe for both nutritional and medicinal uses. The $\mathrm{LD}_{50}$ for the aqueous extracts of Vitex simplicifolia was also noted to be above $5000 \mathrm{mg} / \mathrm{kg} /$ per oral route; this agrees with the findings of Rathi et al. ${ }^{22} \mathrm{~A}$ chemical substance with $\mathrm{LD}_{50}$ greater than $5000 \mathrm{mg} / \mathrm{kg} /$ oral route could be considered of low toxicity and safe. ${ }^{25}$ Therefore, lack of associated lethality with doses of Moringa olifera and Vitex simplicifolia extracts used herein, was an indication that both are relatively safe on acute oral exposure.

\section{Aqueous leaf extract administration}

On each day, experimental rats were weighed and their baseline blood glucose levels measured using a glucometer. Subsequently, distilled water, standard doses $(300 \mathrm{mg} / \mathrm{kg} /$ per oral) of leaf extracts of both plants, as well as glibenclaimide $(10 \mathrm{mg} / \mathrm{kg} / \mathrm{per}$ oral) were administered to normoglycemic and diabetic rats per oral using $1 \mathrm{~mL}$ syringe on the first and second days of experiments.

Table 1. Comparison of the Effect of Aqueous Leaf Extracts of Moringa oleifara, Vitex simplicifolia and Glibenclamide on Normoglycemic Rats.

\begin{tabular}{lcccccccc} 
Treatment groups & $0 \mathrm{hr}$ & $1 \mathrm{hr}$ & $2 \mathrm{hr}$ & $4 \mathrm{hr}$ & $6 \mathrm{hr}$ & $8 \mathrm{hr}$ & $10 \mathrm{hr}$ & $12 \mathrm{hr}$ \\
Group 1 & $84.67 \pm 4.055$ & $86.67 \pm 3.844$ & $83.00 \pm 4.359$ & $84.67 \pm 4.096$ & $85.00 \pm 4.041$ & $86.00 \pm 4.359$ & $84.00 \pm 4.619$ & $84.33 \pm 4.055$ \\
Group 2 & $88.34 \pm 6.429$ & $86.00 \pm 0.577$ & $85.33 \pm 0.333$ & $67.67 \pm 0.333$ & $63.33 \pm 0.333$ & $61.00 \pm 0.577$ & $57.67 \pm 0.333^{*}$ & $55.00 \pm 0.000^{*}$ \\
\hline Group 3 & $87.33 \pm 5.925$ & $82.33 \pm 6.627$ & $76.33 \pm 0.333$ & $65.00 \pm 0.000$ & $61.00 \pm 0.000^{*}$ & $58.33 \pm 0.333^{*}$ & $56.000 \pm 0.333^{*}$ & $53.00 \pm 0.000^{*}$ \\
Group 4 & $87.51 \pm 3.215$ & $80.33 \pm 2.028$ & $58.67 \pm 0.882$ & $56.33 \pm 0.882$ & $52.00 \pm 1.155^{*}$ & $47.33 \pm 0.882^{*}$ & $45.00 \pm 0.577^{*}$ & $41.00 \pm 0.577^{*}$ \\
\hline
\end{tabular}

$* \mathrm{P} \leq 0.05$. 


\section{Estimation of fasting blood glucose level}

Using lancets, each rat's tail was pricked and gently squeezed until a drop of blood was allowed on to the test strip attached to the glucometer slot; results of blood glucose levels $(\mathrm{mg} / \mathrm{dL})$ were recorded after $0,1,2,4$, $6,8,10$ and 12 hours intervals.

\section{Ethical approval}

Ethical clearance for the study was obtained from the Scientific and Ethical Committee of the Collage of Health Sciences, Bayero University, Kano-Nigeria.

\section{Statistical analyses}

Data was expressed as Mean \pm SEM. One-way ANOVA was used to determine hypoglycemic differences with respect to the two leaf extracts; Bonferoni hoc test was also used to confirm the differences between them. All analyses were carried out using SPSS version 20.0 statistical software. $\mathrm{P}<0.05$ was set as level of significance.

\section{Results}

Significant hypoglycemic effects of Moringa oleifera was noticed after 10 hours, while that of Vitex simplicifolia within 6 hours after oral administration (Table 1). Percentage maximum reduction at the end of the experiment in blood glocuse levels (Table 2) caused by the aqueous leaf extracts were 37.7 and $39.3 \%$, respectively. These values were significantly different from that of the negative control, when compared to that of glibenclamide $(53.1 \%)$.

Table 3 shows significant decrease in blood glucose concentration caused by both leaf extracts after oral administration. The antidiabetic effect of Moringa oleifera was noticed within 6 hours after oral administration, and continued to lower the blood glucose till the end of the experiment. On the other hand, the antidiabetic effect of Vitex simplicifolia was noticed within 4 hours after oral administration and the percentage maximum decrease at the end of the experiment in blood glucose levels caused by leaf extracts of these plants were 64.82 and
$66.1 \%$, respectively. Observed antidiabetic effects of both extracts were greater than that of the reference drug, glibenclamide $(64.48 \%)$

\section{Discussion}

Short-term exposure of $\beta$-cells of the pancreas to increasing glucose concentrations induces their proliferation in a concentration-dependent manner. ${ }^{23}$ At the same time, the secretary function of these cells is impaired; this action takes place before apoptosis leads to a significant decrease in $\beta$-cell mass. ${ }^{26}$

In this study, oral administration of the investigated leaf extracts exhibited both hypoglycemic and antidiabetic activities with clinical significance. The extracts also competed favorably with the reference drug, glibenclamide. The hypoglycemic and antidiabetic activities of Moringa oleifera agrees with an earlier report by Luka, et al, 2013. ${ }^{27}$ At the given dose, the efficacy of Moringa oleifera in reducing glucose level in normoglycaemic and diabetic rats were observed. It continued to lower the blood glucose levels of these group of animals till the end of the $12^{\text {th }}$ hour. Oral administration of this same of aqueous extract caused a significant reduction of $64.82 \%$ in alloxaninduced diabetic rats; this agrees with the findings of Tiwari, Rao, 2002.28 The blood glucose leveling effect of $300 \mathrm{mg} / \mathrm{kg} /$ per oral of Moringa oleifera was higher than that of glibenclamide and lower in Vitex simplicifolia. This indicates the presence of active ingredients (phytochemicals) that have potent hypoglycemic properties in
Moringa oleifera. Flavonoids are very important natural phenolics which poses radical scavenging properties. ${ }^{29}$ Furthermore, an earlier report by Yeh et al. ${ }^{30}$ revealed that, quercetin is another strong antioxidant phytochemical present in Moringa oleifera; it significantly increases hepatic glucose kinase activities as an insulin-like effect, thereby increasing tissue utilization of glucose by cells. Another report has also shown that, the antidiabetic effect of Moringa oliefera may be due to the presence of terpenoids, which appear to be involved in the stimulation of $\beta$-cells and hence, secretion of preformed insulin. ${ }^{31}$

The observed hypoglycemic and antidiabetic effects of the two herbs used in this study is an indication that, the herbs may contain potent substances with potent hypolglycemic and antidiabetic activities as present in other medicinal plants with antihyperglycemic properties, and this is an agreement with an earlier report. ${ }^{28}$ Some of the substances may have multi-directional biological activities, including hypoglycemic and antidiabetic effect in lowering blood glucose level. ${ }^{29}$ The herbs might also contained micronutrients such as vanadium, copper and manganese (as present in other plants with antidiabetic effect), which have insulin-like activities as well as upregulation of insulin receptors; and this could be responsible for their blood glucose lowering effect. ${ }^{15}$ These micronutrients might also affect glycemic control noticed in this study, by facilitating glucose uptake and metabolism as well as enhancement of insulin sensitivity; and clinically, they might enhance glucose oxidation and glycogen synthesis as well as modulating hepatic

Table 2. Maximum Percentage Reduction of Glucose Levels after Administration of Moringa oleifara and Vitex simplicifolia Leaf Extracts and Glibenclamide by Normoglycemic Rats.

\begin{tabular}{lcc} 
Treatment Groups & Maximum Reduction (mg/dL) & Maximum Reduction (\%) \\
Group 1 & 0.34 & 0.01 \\
Group 2 & 33.34 & $37.7^{*}$ \\
\hline Group 3 & 34.33 & $39.3^{*}$ \\
Group 4 & 46.51 & $53.1^{*}$ \\
\hline * $\leq 0.05$. & &
\end{tabular}

Table 3. Comparison of the Effect of Leaf Extracts of Moringa Oleifara, Vitex simplicifolia and Glibenclamide on Diabetic Rats.

\begin{tabular}{lcccccccc} 
Treatment Groups & $0 \mathrm{hr}$ & $1 \mathrm{hr}$ & $2 \mathrm{hr}$ & $4 \mathrm{hr}$ & $6 \mathrm{hr}$ & $8 \mathrm{hr}$ & $10 \mathrm{hr}$ & $12 \mathrm{hr}$ \\
Group 1 & $217.33 \pm 1.764$ & $218.67 \pm 1.667$ & $215.33 \pm 0.764$ & $215.00 \pm 0.000$ & $215.67 \pm 1.453$ & $215.33 \pm 1.202$ & $220.00 \pm 1.155$ & $213.00 \pm 2.646$ \\
Group 2 & $259.67 \pm 40.786$ & $248.67 \pm 42.916$ & $227.33 \pm 42.807$ & $193.67 \pm 37.949$ & $126.67 \pm 14.847^{*}$ & $114.6 \pm 13.246^{*}$ & $108.0 \pm 5.196^{*}$ & $91.33 \pm 13.776^{*}$ \\
\hline Group 2 & $254.67 \pm 31.798$ & $213.67 \pm 32.220$ & $113.67 \pm 33.448^{*}$ & $98.33 \pm 6.888^{*}$ & $95.33 \pm 16.756^{*}$ & $91.33 \pm 21.697^{*}$ & $92.33 \pm 9.528^{*}$ & $86.33 \pm 2.186^{*}$ \\
Group 3 & $239.33 \pm 0.667$ & $268.00 \pm 0.578$ & $240.67 \pm 0.667$ & $235.67 \pm 0.333$ & $140.33 \pm 0.333^{*}$ & $90.33 \pm 0.333^{*}$ & $83.33 \pm 0.333^{*}$ & $85.00 \pm 0.578^{*}$ \\
\hline$* \mathrm{P} \leq 0.05$ & & & & & & & &
\end{tabular}


Table 4. Maximum Percentage Reduction of Glucose Levels after Administration of Moringa oleifara and Vitex simplicifolia Leaf Extracts and Glibenclamide in Diabetic Rats.

\section{Treatment Groups} Maximum Reduction (mg/dL) Maximum Reduction (\%)

\begin{tabular}{lcc} 
Group 1 & 4.33 & 0.02 \\
Group 2 & 168.34 & $64.82^{*}$ \\
\hline Group 3 & 168.34 & $66.1^{*}$ \\
Group 4 & 154.33 & $64.48^{*}$ \\
\hline
\end{tabular}

${ }^{*}$ Mean \pm SEM $(\mathrm{P} \leq 0.05)$.

glucose output. ${ }^{31}$ At the same time, the blood lowering activity of the herbs may be as a result of the antioxidants, vitamins $\mathrm{C}$ and $\mathrm{E}$ ), as well as enzymes present in them. ${ }^{32}$ These antioxidants act as potent metal chelators as well as free radical scavengers, and these properties may be responsible for stabilization of reactive oxygen species induced by alloxan in the diabetic rats, thereby reversing their damaging effect on pancreatic beta cells and hence, secretion of preformed insulin. This means the two herbs used in the experiment possess antioxidant properties which could have reversed the cytotoxic cycle of the alloxan in the pancreas or mobbed up the reactive oxygen species in circulation, thereby reducing the effect of oxidative stress on the pancreatic beta cells and subsequent insulin secretion. ${ }^{15}$ The anti-hyperglycemic effect in this study could also be as a result of stimulation of the pancreatic beta cells by some of the ingredients present in them leading to secretion of preformed insulin and subsequent lowering of blood sugar level, ${ }^{32}$ i.e. some of the herbs could have behaved as insulin secretagogues. Furthermore, some of the substances present in the herbs might have lowered the blood glucose level by acting as both insulinomimetics and insulin secretagogues. ${ }^{23}$

Another possible mechanism by which the herbs reduced the blood glucose levels may involve inhibition of alpha-glucosidase activity in the intestinal brush border, and this may prevent non-Sodium-dependent mechanism in facilitating diffusion of monosaccharides through the intestinal epithelia, ${ }^{33}$ and consequently, $\mathrm{Na}^{+}$-dependent transport for monosaccharides is arrested; ${ }^{34}$ thereby reducing the absorption glucose from the gastrointestinal tract and thus, controlling postprandial hyperglycemia. ${ }^{35}$ Furthermore, some of the ingredients present in the herbs could act by significantly increasing their hepatic glucosekinase thereby enhancing the uptake of glucose from circulation; the glucose would subsequently be phosphorylated and then temporarily trapped inside liver cells for the synthesis of glycogen. ${ }^{36}$ The herbs may also exert their effect by increasing tissue uptake of glucose, by enhancement of insulin sensitivity. ${ }^{37}$

Finally, it was observed that, aqueous leaf extracts of Vitex simplicifolia had rapid onset of antidiabetic activities than Moringa oleifera and glibenclamide. On the other hand, Moringa oleifera had a longer or sustained antidiabetic action than Vitex simplicifolia and glibenclamide. It was also noticed that, the leaf extract of Vitex simplicifolia had the highest antidiabetic effect at the end of the experiment, followed by Moringa oleifera. All the two aforementioned herbs investigated were more potent than the reference drug, glibenclamide.

As a limitation of this study, 'the toxic action of alloxan monohydrate resulted to changes in the structural conformation and function of not only the glucokinase enzyme.

\section{Conclusions}

The two herbs have potent oral hyperglycemic properties, which could be as a result of the phytochemicals present in them; their effects of the two investigated aqueous extracts were different - that of Vitexsimplifolia has a faster onset of action than Moringa oleifera and glibenclamide at the doses used. Aqueous leaf extract of Moringa oleifera has a longer antidiabetic effect than Vitex simplicifolia and glibenclamide. It was also found out that, he antidiabetic effects of the two extracts are greater than that of the reference drug, glibenclamide.

Considering the findings and importance of the study, it could be recommended that, the two herbs have potent oral hyperglycemic properties, which could be as a result of the phytochemicals present in them; the effects of the two investigated extracts were different - aqueous leaf extracts of Vitexsimplifolia has a faster onset of action than Moringa oleifera and glibenclamide at the doses used; aqueous leaf extract of Moringa oleifera has a longer antidiabetic effect than Vitex simplicifolia

\section{Recommendations}

and glibenclamide; the efficacy of Vitex simplicifolia in lowering blood glucose level is higher than that of Moringa oleifera.

\section{References}

1. International Diabetes Federation (IDF). Definition and diagnosis of diabetes mellitus and intermediate hyperglycemia: Report of a WHO/IDF consultation. Geneva: WHO, 2006. Available from: www.ncbi.nlm.nih.gov.

2. World Health Organization (WHO). (2018). Diabetes. Available from: https://www.who.int/news room/factsheets/detail/diabetes.

3. Sarwar N, Gao P, Seshasai SR, et al. Diabetes mellitus, fasting blood glucose concentration, and risk of vascular disease: a collaborative meta-analysis of 102 prospective studies. Emerging Risk Factors. Lancet 2010;26:2215-22.

4. Tukur D, Alhaji A Aliyu, Shehu AU. A review of population-based studies on Diabetes mellitus in Nigeria SubSaharan Afr J Med 2016;3:59-64.

5. Anthonia OO, Chukwuma E. Diabetes mellitus in Nigeria: The past, present and future. World J Diabetes 2014;5: 905-11.

6. World Health Assembly Follow up to the political Declaration of the Highlevel Meeting of the General Assembly on prevention and Control of Non-communicable Diseases, Geneva WHO, 2013. In: Tukur D, Alhaji A Aliyu, Shehu AU. A review of populationbased studies on Diabetes mellitus in Nigeria. Sub-Saharan African J Med 2016;3(2): 59-64.

7. Type I Diabetes. Retrieved 29th October, 2019. Available from: https://www.mayoclinic.org/diseasesconditions/type-1-diabetes/symptomscauses/syc-20353011.

8. Ugege O, Ibitoye PK, Jiya MM. Childhood Diabetes mellitus in Sokoto, North-Western Nigeria. A Ten-year Review. SAHEL Med J. 2013; 16:97101.

9. Wokoma FS, John CT, Enyindah CE. Gestational Diabetes in a Nigerian antenatal population. Trop J Obstet Gynaecol 2001;18:56-60.

10. National Diabetes Statistics (NDS) National diabetes information clearing house. [Serial on the internet]. Retrieved Jun 2014. Available from: http://diabetes.niddk.nih.gov/dm/pubs/s tatistics.

11. Viana GS, Medeiros AC, Lacerda AM, et al. Hypoglycemic and anti-lipemic 
effects of the aqueous extract from Cissussicyoides. BMC Pharmacol 2004;8:4-9.

12. Iranloye BO, Arikawe AP, Rotimi G, Sogbade AO. Anti-diabetic and antioxidant effects of Zingiberofficinale on alloxan-induced and insulin-resistant diabetic male rats. Nig J Physiol Sci 2011;26:89-96.

13. Gul E, Akturk U. Complementary and alternative treatment methods Used in Adults with Diabetes in Turkey. Global J Endocrinol Metabol 2018;2.

14. Rates, SM. Plant as a source of drug. Toxicon 2001;39:603-13.

15. Mfon I, Akpaso, Item J, et al. Effect of combined leaf extracts of Vernoniaamygdalina and Gongronemalatifolium on the pancreatic beta cells of Streptozotocin-induced Diabetic Rats. Br J Med Med Res 2011;1:24-34.

16. Ginsberg H, Rayfield EJ. Effect of insulin therapy on insulin resistance in type II diabetic subjects. Diabetes 1981;30:739-45.

17. Gupta AK, Mishra SK. Indigenous phytotherapy for diabetes from Chattisgarh. Adv Plant Sci 2002;15:407-9.

18. Akhar PA, Okafor CL. Blood sugar lowering effect of Veroniaamygdalina in an experimental rabbit model. Phyto Res 1992;6:171-3.

19. Yakubu OE, Ojogbane E, Nwodo OFC, et al. Comparative antioxidant and hypoglycemic effects of aqueous, ethanol and n-hexane leaf extracts of Vitexdonianaon streptozotocin-induced diabetes in albino rats. Acad J 2013;12:5933-40.

20. Burkill HM. The Useful Plants of West
Tropical Africa. 2nd ed. Kew: Royal Botanic Garden; 2000. p. 272-5.

21. Burcelain RM, Eddouks J, Maury J, et al. Excessive Fasting Blood glucose in Diabetes. Diabetolgia 1995;38:283-90.

22. Rathi BS, Bodhankar SL, Baheti AM. Evaluation of aqueous leaves extract of Moringa oleifera Linn for wound in albino rats. Indian J Exp Biol 2006;44: 898-901.

23. Nagy MA, Mohammed SA. Anti-diabetic effects of Cleome droserifolia. Am J Biochem 2014;4:68-75.

24. Nwogo AO, Kalu MK, Uchechukwu O, Glory O. Hypoglycemic effects of aqueous and methanolic leaf extracts of Vitex doniana on alloxan-induced diabetic albino rats. J Med Sci 2013;13: 700-7.

25. Meraiyebu A, Ogunwole E, Izuchukwu NS. Effects of aqueous extract of Moringa oleifera seeds on alloxaninduced hyperglycaemic. Basic Sci Med 2014;3:37-42.

26. Donath MY, Halban PA. Decreased beta-cell mass in diabetes: significance, mechanisms and therapeutic implications. Diabetologia 2004;47:581-9.

27. Luka CD, Tijjani H, Joel EB, et al. Hyperglycemia properties of aqueous extracts of Anarcardiumoccidentale, Moringaoleifera, Vernoniaamygdalina and Hlianthusanuus. Int $\mathrm{J}$ Phar Sci Invent 2013;2:16-22.

28. Tiwari AK, Rao JM. Diabetes mellitus and multiple therapeutic approaches of phytochemicals: Present status and future prospects. Curr Sci 2002;83:307.

29. Szkudelski T. The Mechanism of Alloxan and Streptozotocin Action in B Cells of the Rat Pancreas. Physiol Res
2011;50:536-46.

30. Yeh GY, Eisenberg DM, Kaptcuk TJ, Philips RS. Systemic review of herbs and dietary supplements for glycemic control in diabetes. Diabet Care 2003;26:1277-94.

31. O'Connell B. Selected vitamins and minerals in the management of diabetes. Diabetes Spectr 1999;14:133-48.

32. Tende JA, Ezekie I, Dikko AAU, Goj ADT. Effect of ethanolic leaves extract of Moringa oleifera on blood glucose levels of streptozotocin-induced diabetes and normo-glycaemic Wistar rats. Brit J Pharm Tox 2011;2:1-4.

33. Andrade-Cetto A, Jimenez JB, Vazquez RC. Alfa-glucosidase-inhibiting activity of some Mexican plants used in the treatment of type II diabetes. J Ethnopharm 2008;116:27-32.

34. Cazarolli LH, Zanatta L, Alberton EH, et al. Flavonoids: cellular and molecular mechanism of action in glucose homeostasis. Mini Rev Med Chem 2008;8:1032-8.

35. Ali MM, Abdu El, Kader MA. The influence of Naringin on the oxidative states of rats with Streptozotocininduced acute hyperglyacamia. Z Naturforsch 2004;59c:726-33.

36. Vessal M, Hemmati M, Vasei $M$. Antidiabetic effects of quercetin in streptozocin induced diabetic rats. Comp Biochem Physiol 2003; 135C: 357-64.

37. Nandhini AT, Thirunavukkarasu V, Anuradha CV. Stimulation of glucose utilization and inhibition of protein glycation and AGE products by taurine. Act Physiol Scandmavica 2004;181: 297-303. 